\title{
Importance of Including the Role of Clinical Medical Librarian in Library and Information Science Curriculum Development:
}

\section{A Review}

\author{
M. P. P. Dilhani ${ }^{1}$
}

\begin{abstract}
Today Clinical Medical Librarianship fulfill many critical roles in the hospital setting by providing the correct information at the right time in a variety of ways to enhance the effectiveness in productivity of hospitals and medical staff. The other roles that have to play are optimize patient care, improve patient outcomes, and increase patient \& family satisfaction about the services provided by the hospital. As Clinical Medical Librarians (CMLs) and their services provide an excellent return on investment for the hospital and help keeping its competitive edge, hospital staff should have access to the services of a professional librarian. The aim of this study is to use the findings from the literature to highlight the necessity of the Library and Information Science (LIS) curriculum to contain the role of the CML as well as the specialization course content of Clinical Medical Librarianship covering content distribution, learning protocol, and practical planning. Thus, the results of this study can be used as the basis for future developments in the Library and Information Science curriculum to provide a more appropriate and detailed curriculum that covers the required pedagogy on Clinical

${ }^{1}$ Senior Assistant Librarian, Postgraduate Institute of Medicine, University of Colombo.

Email: dilhani@pgim.cmb.ac.lk (iD https://orcid.org/0000-0002-8351-6568

\begin{tabular}{|c|c|}
\hline (c) (7) (2) & Received: 20 March 2021, Accepted revised version: 25 May 2021 \\
\hline
\end{tabular}
\end{abstract}


Librarianship. Relevant research articles published in 2000-2020 August were selected through a literature search. The 575 of those selected articles were further scrutinized for relevance and uniqueness. Then the three hundred twelve articles were selected for this study considering the relevance to emerging roles, professional settings, and contexts of CMLs. The importance of generating CMLs with the requisite skills, knowledge, and certifications is revealed by this study. As a result, it is suggested that a syllabus outlining the role of CML be added into the existing LIS curriculum in Sri Lanka. Further study recommended that the role of CML has evolved to meet the demands of healthcare now by taking their skills and expertise to the point of need and the role of CML appears to be an important member of the medical team, according to this study.

Keywords: Clinical Medical Librarians, Clinical Medical Librarianship, Library and Information Science Curriculum, Sri Lanka, LIS Education 


\section{Introduction}

The term "Clinical Librarian" was first used in 1971 by Gertrude Lamb of the University of Missouri at Kansas City (UMKC) School of Medicine. Lamb first conceived the concept of Clinical Librarianship when she was invited to develop a computer system to assist medical students' self study while serving as a Clinical Librarian at the University of Missouri Medical School. She studied with her students and demonstrated the uniqueness of the role of Medical Librarians in medical clinics by providing information on clinical questions asked by physicians during the medical round. Expanding the role of the Clinical Librarian then introduced by Gertrude Lamb, to a new profession today, is closely linked to the healthcare system, which identifies the information needs of healthcare providers and patients (Lappa, 2009).

Today the unique role of the CMLs has become more prominent, surpassing the role of the hospital librarian. CMLs provide health related medical information such as new therapeutics, clinical and standardized tests, guidelines, treatment modalities, drug monographs for the clinicians, nurses, allied health professionals, and other members, and the public at a time when information is needed for diagnostic process, treatment plan and general instructions. However, compared to the programmes and degrees offered for CMLs in the world, it is arguable if the current Master's programme in Library and Information Science (LIS) in Sri Lanka lack in providing adequate educational preparation for students who wish to work in the field of health information (Detlefsen, 2012). Since the provision of health information services is rapidly evolving, and a need for specialized library professionals is rising, it is essential to focus on creating and updating the cross disciplinary 
curriculum of higher vocational education (Detlefsen, 2012; Greyson et al., 2013). Specifically, outdated curricula and specific learning outcomes are often overlooked by the current emerging demands and challenges faced by healthcare libraries (Blake \& Ballance, 2013; Wilson, 2008).

Furthermore, LIS educationalists have failed to develop in them an adequate understanding of the required training for Evidence Based Medicine (EBM) and updating CMLs activities through learning the LIS series (Detlefsen, 2012; Greyson et al., 2013; Lasserre, 2012; Dilhani et al., 2020). It has resulted in the issue of inadequate guidance and counselling for the students of the LIS who are pursuing a career as CMLs and then moving on to continuous professional development based on the general knowledge of librarianship which disconnects them from the specific skills requirements for it (Cooper \& Crum, 2013).

In 2017, the Medical Library Association (MLA) published an updated list of professional competencies for Health Information Professionals (HIPs) titled "Competencies for Lifelong Learning and Professional Success," which includes (1) information services (2) information management (3) instruction and instructional design (4) leadership and management (5) evidence based practice and study and (6) health information professionalism (Medical Library Association [MLA], 2017). These skills typically focus on community outreach, user centered learning, current trends, application of evidence based practice principles to librarianship, and technology enhancing learning. CMLs serve educators, students, health care providers, researchers, and the general public at a time when information for counseling, clinical training, research, and personal health management is changing widely. Furthermore, only through Library Science courses, LIS educators fail to 
provide the students with a proper understanding of EBM practice and skills needed for CMLs. As a result, there is a gap between librarianship's general knowledge base and Clinical Medical Librarianship's specialized competency criteria (Ma et al., 2018). Attempts were made to review this scope to contextualize those professional skills and link them to the use of practical health information, to identify basic and theoretically achievable evolving CMLs skills and related professional settings through LIS curriculum development. It further extended to core journals in LIS as well as specialized health care journals.

\section{Problem Statement}

Changes in medical information together with education and healthcare have revolutionized the healthcare delivery system. In this context, the provision of health science/medical information service has become a specialized library professional field which is rapidly evolving (Ma et al., 2018). In line with these changes, health information professionals are compelled to move away from their traditional roles to take on new roles in order to meet the emerging needs of their users. The role of CML is becoming important in many aspects and becomes essential in certain situations in the university and clinical settings. With emerging needs and future trends, it is envisaged that a pool of trained and skilled, CMLs will be a necessity for the health care delivery system of the country. These librarians should be equipped with required competencies to face challenges. Therefore, it is important that a mechanism should be available for them to acquire the necessary knowledge and skills through the LIS in the country. 


\section{Objective of the Study}

There is a need for the roles of CMLs in the Sri Lankan Library system. Therefore, the objective of the article is to introduce the concept of the CML into the LIS curriculum of the Sri Lankan system by reviewing the literature.

In this context, the following two research questions need to be addressed when introducing CMLs as an essential component of LIS education in Sri Lanka.

\section{Research Questions}

- Based on the research published from 2000 to 2020, how do the professional role of CMLs and their activities evolve?

- Could these identified roles be mapped on to the emerging needs and future trends of the Sri Lankan context and recommend the importance of inclusion of the role of CMLs in the LIS programmes in Sri Lanka?

\section{Research Methodology}

Databases searched included ScienceDirect, PubMed, EBSCO and HINARI. Search queries were tailored for different databases according to their respective controlled vocabularies:

1. ("clinical medical librarian" [All field] OR "hospital librarian" [All field] OR "medical librarian" [All Field] OR "libraries, medical" [MeSH] OR "librarians" [MeSH]) AND ("role" [All field] OR "professional role" $[\mathrm{MeSH}])$

2. ["health information professional" OR "medical librarian" AND role] for ScienceDirect 
3. ["health information professional" OR "medical librarian" AND "roles and responsibilities"] for ScienceDirect and EBSCO

4. ["health sciences librarian" AND role] for ScienceDirect and EBSCO

Research articles were retrieved from the publication year 2000August 2020. The researcher scrutinized the 575 articles for relevance and uniqueness. Three hundred twelve articles were selected as study units relevant to emerging roles, professional settings, and contexts of CMLs.

\section{Results}

In approximate order of frequency or primacy of selected articles $(n=312)$, the foremost roles emerged as 6 distinct categories: (1) Teacher $(\mathrm{n}=65)$; (2) Expert Searcher $(\mathrm{n}=63)$; (3) Communicator $(\mathrm{n}=74)$; (4) Collaborator ( $\mathrm{n}=68$ ); (5) Patient Advocate ( $\mathrm{n}=64)$; (6) Content Manager $(n=64)$. The term "embedded librarians" emerged as a stand out theme. While the definition varied across studies, overarching themes indicated that CMLs are taking on more active roles and functioning as teachers, collaborators, research experts, scholars, and content managers rather than more passive and exclusive roles as information providers, information outreach agents, or research assistants (Blakeet et al., 2014). With such a large and loosely established professional position for CMLs, it is difficult to reach a consensus when it comes to linking embedded librarianship to needed professional core competencies, as well as meeting the research objectives of the study. As a result, embedded librarians' responsibilities were divided into distinct positions based on their actual job responsibilities (Hageman, 2019; Hinrichs et al., 2020; Ma et al., 2018). 
Figure 1 depicts the six types of professional positions that emerged from this study. These technical positions or environments are roughly ranked based on the literature's frequency and focus. The most common types of professional duties or responsibilities as they appear in the literature are the defined core duties of each category of professional role. Each type has its own distinct characteristics.

\section{Figure 1}

\section{Mapping the CMLs' Roles to the Sri Lankan Context}

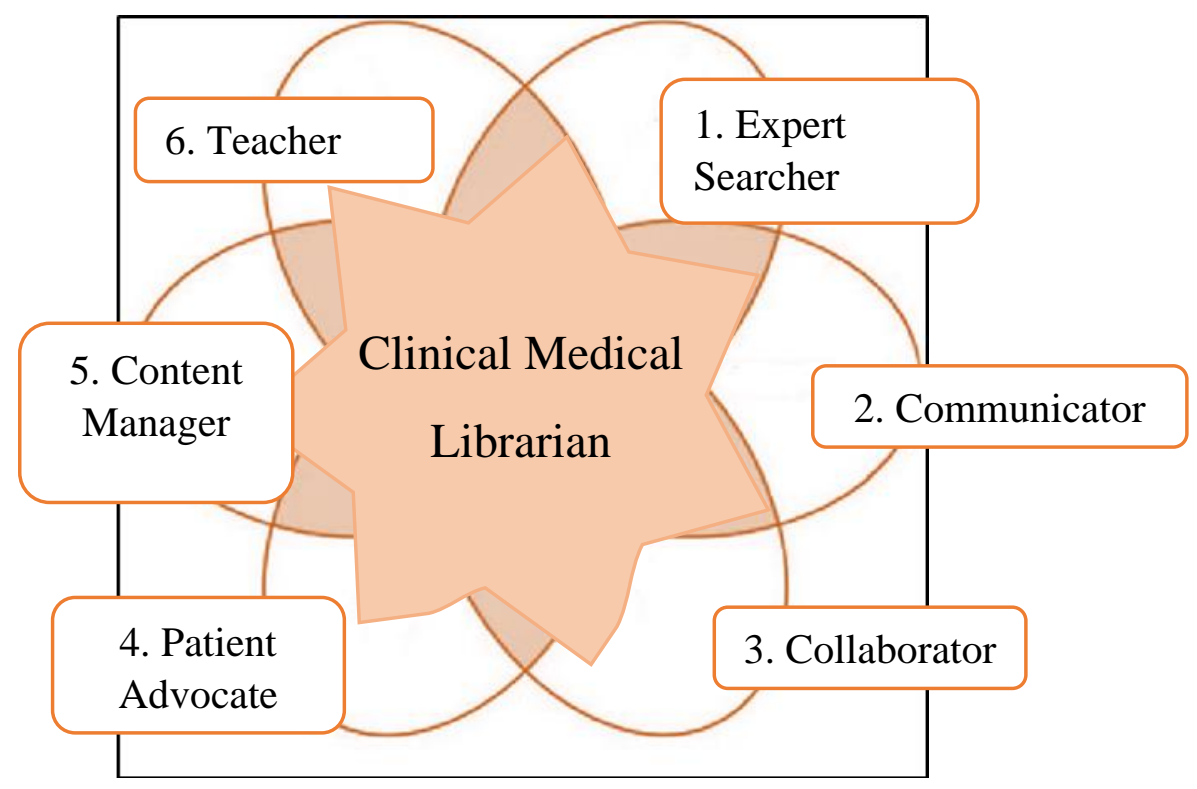

Note. Compiled by researcher based on the literature

The following reasons create barriers to the availability of necessary information reaching medical team members; such as the rapid growth of literature and the emergence of new topics in medicine, combined with the busy schedules of physicians and medical teams, complicated by the variety of information sources and a lack of knowledge about various databases and search methods. Figure 1 shows 
how CMLs attempt to understand and participate in a variety of activities outside of the library, including curriculum and research, as well as providing teaching and training to support evidence based practice. These activities will necessitate a high level of more complex abilities, as well as more engagement between CMLs and medical team, patients and community service programs.

CMLs must possess a variety of abilities in order to successfully fulfill their responsibilities of supplying information to medical teams. Various studies have discussed CMLs' responsibilities and roles, as well as the various vital talents that they must possess in order to work on clinical teams as shown in the Table 1.

\section{As an Expert Searcher}

As an expert searcher, CML assists and guides medical students and other affiliated healthcare professionals on how to use medical software programmes, online databases, online resources, how to use search engines for EBM, and how to search the Internet for up to date as well as other medical health related information and services. Expert searching is characterized as a mediated process in which a patient with an information need seeks advice and assistance from a recognized expert, as defined by the MLA (2005) in the sense of this policy document. The known expert leads a quest that brings together and synergizes all of the essential skills and knowledge. 


\section{Table 1}

Required Skills, Abilities Needed Specific Duties for CMLs Based on Reviewed Literature

\begin{tabular}{|c|c|}
\hline Role & No. of \\
\hline
\end{tabular}

Expert searcher $\quad 302 \quad$ Providing end-user searchers with expert advice (MLA, 2005; Lasserre, 2012; Joshi et al., 2014)

Design of online searching education programs (MLA, 2005; Hackstadt, A., 2020)

Providing professional advice on a health-care informatics application (MLA, 2005; Hageman, 2019; Brady \& Kraft, 2012)

Providing highly specialized services like CMLs programs or clinical or research information specialist in context programs (MLA, 2005; Butson \& Pauly, 2013)

Creating gold standard searches and expert "hedges" for colleagues and end users to use (MLA, 2005;

Swanberg et al., 2016; Sullo \&
The ability to correctly recognize a need for information through successful personal interaction.

Understanding of the subject domain knowledge and sensitivity to professional information.

The ability to grasp the consequences of the information requirement through the institution's relevant institutional knowledge mission.

The ability to locate and search resources outside of the written literature that is available electronically

Awareness of personal searcher constraints in relation to the subject domain

Understanding of database content, indexing, and metadata conventions

Specialist knowledge of retrieval system interfaces to choose which interface is most appropriate 


\begin{tabular}{|c|c|c|c|}
\hline Role & $\begin{array}{l}\text { No. of } \\
\text { articles }\end{array}$ & Specific duties & Skills and abilities needed \\
\hline & & $\begin{array}{l}\text { Gomes, 2016) } \\
\text { Creating expert-searching continuing } \\
\text { education courses or other peer- } \\
\text { to-peer learning possibilities } \\
\text { (MLA, 2005) }\end{array}$ & $\begin{array}{l}\text { Skilled use of logical, positional, and } \\
\text { weighing capabilities of retrieval } \\
\text { systems; ability to be conscious and } \\
\text { reflective. } \\
\text { To consider and evaluate what is being } \\
\text { recovered using an iterative and } \\
\text { heuristic search procedure for finding } \\
\text { relevant evidence. } \\
\text { Demonstrated ability to employ both logical } \\
\text { and inductive thinking, as well as } \\
\text { knowledge of the subject topic } \\
\text { Ability to efficiently and effectively } \\
\text { evaluate retrieved evidence. } \\
\text { The ability to expertly analyze retrieval in } \\
\text { order to provide results by removing } \\
\text { extraneous information from search } \\
\text { results. } \\
\text { The capacity to effectively document the } \\
\text { search process for end-user information } \\
\text { or legal retention. }\end{array}$ \\
\hline Communicator & 296 & $\begin{array}{l}\text { Providing necessary information for } \\
\text { patients, their families and } \\
\text { medical team (Hageman, 2019); } \\
\text { Providing necessary information } \\
\text { sources about the disease to the }\end{array}$ & $\begin{array}{l}\text { Information searching on diseases } \\
\text { Oral presentation } \\
\text { Electronic communication skills } \\
\text { Answer clinical questions and directly } \\
\quad \text { support clinical care }\end{array}$ \\
\hline
\end{tabular}




\begin{tabular}{|c|c|c|c|}
\hline Role & $\begin{array}{l}\text { No. of } \\
\text { articles }\end{array}$ & Specific duties & Skills and abilities needed \\
\hline Collaborator & 262 & $\begin{array}{l}\text { patients (Li et al., 2013) } \\
\text { Facilitating clinical decisions (Cooper } \\
\text { \& Crum, 2013; Li et al., 2013; } \\
\text { Sullo \& Gomes, 2016) } \\
\text { Patient care and patient education for } \\
\text { them (Aldrich \& Schulte, 2014; } \\
\text { Polger, 2010; Sathe et al., 2007). } \\
\text { Butson \& Pauly, 2013) } \\
\text { Electronic medical records, health } \\
\text { informatics, biomedical } \\
\text { informatics, clinical informatics, } \\
\text { consumer health informatics } \\
\text { information retrieval, knowledge } \\
\text { management, EBM (Cruse \& } \\
\text { Protzko, 2014; Murphy \& Boden, } \\
\text { 2015) rounds/morning report, } \\
\text { search support, real time } \\
\text { information searches, nurse } \\
\text { support, institutional decision } \\
\text { making (Hageman, 2019; Hinrichs } \\
\text { et al., 2020; Albert, 2007; } \\
\text { Avallone, 2014; Brandes et al., } \\
\text { 2013; Ma et al., 2018 } \\
\text { Patient education, support for } \\
\text { continuing Medical Education, }\end{array}$ & $\begin{array}{l}\text { Ability to gain the trust of medical team } \\
\text { Familiarity with medical rounds and clinical } \\
\text { settings } \\
\text { Collaboration in developing medical } \\
\text { guidelines } \\
\text { Support outreach efforts, collection } \\
\text { development, and health promotion } \\
\text { programming at public libraries } \\
\text { Support patient education programs, } \\
\text { services, and collections at hospitals } \\
\text { Support outreach to clinical and academic } \\
\text { communities at your institution } \\
\text { Attend health fairs and other community } \\
\text { events }\end{array}$ \\
\hline
\end{tabular}




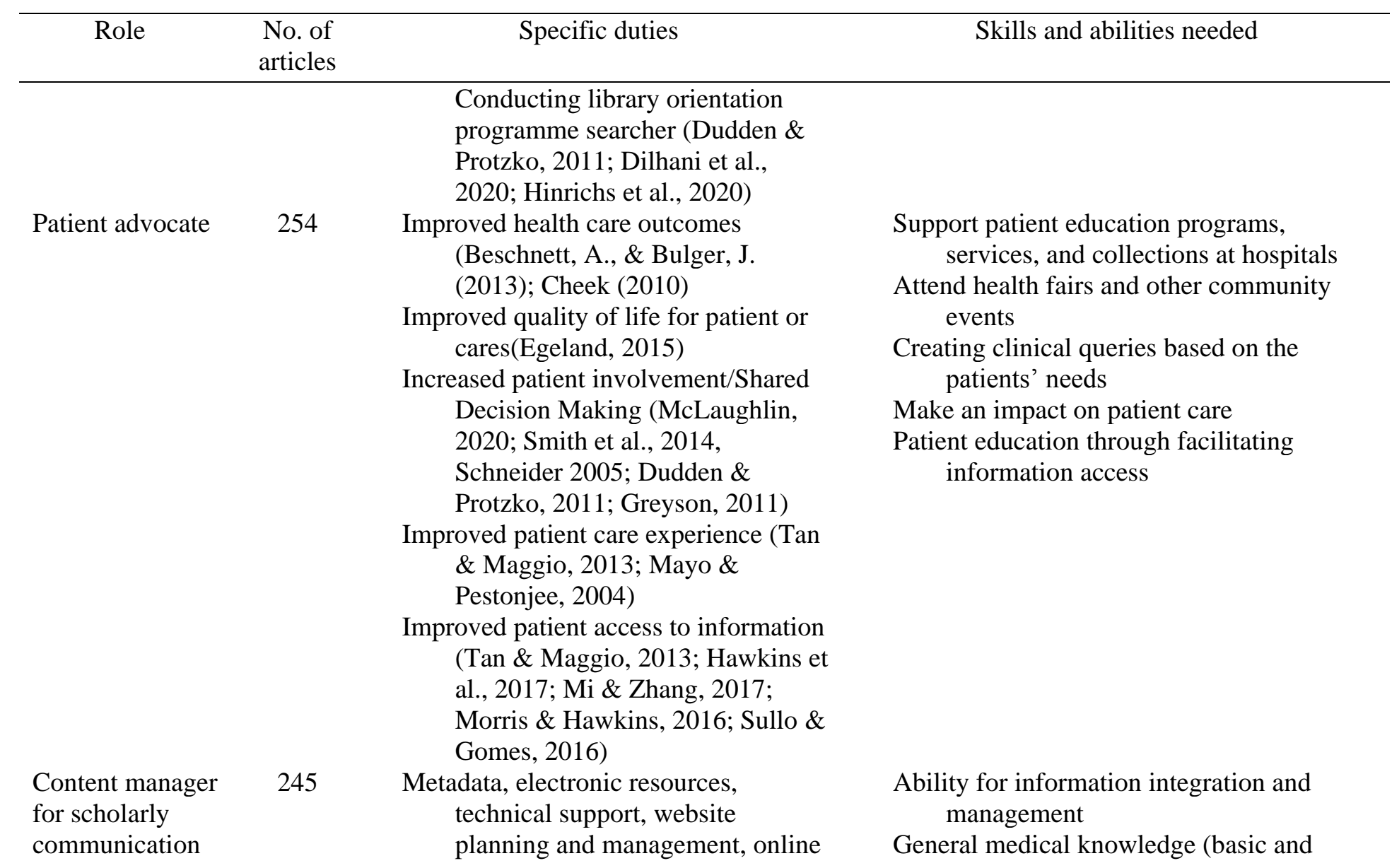




\begin{tabular}{|c|c|c|c|}
\hline Role & $\begin{array}{c}\text { No. of } \\
\text { articles }\end{array}$ & Specific duties & Skills and abilities needed \\
\hline Teacher & 298 & $\begin{array}{l}\text { publishing, EMR compatibility } \\
\text { and interoperability, archive } \\
\text { management, data management, } \\
\text { copyright and intellectual } \\
\text { property, web content } \\
\text { management (Mears \& Bandy, } \\
\text { 2017; Schneider, 2005, Harris et } \\
\text { al., 2013) } \\
\text { Point of need information, instruction, } \\
\text { continuing education, rounds or } \\
\text { morning report institutional } \\
\text { review, public health, cultural } \\
\text { competency, equity and inclusion, } \\
\text { information ethics (King et al., } \\
\text { 2014; Alcock, 2017) } \\
\text { Information literacy, continuing } \\
\text { medical education, group and } \\
\text { individual instruction, in-person } \\
\text { and virtual or remote reference } \\
\text { services, curriculum development, } \\
\text { subject guides (MLA, 2005) }\end{array}$ & $\begin{array}{l}\text { Providing up to date information } \\
\text { Providing teaching information seeking } \\
\text { skills to medical teams and to the } \\
\text { medical team } \\
\text { Conducting systematic reviews } \\
\text { Contribute to continuing education } \\
\text { Provide immediate responses to information } \\
\text { requests at the "point of care" } \\
\text { Define the clinical problem provide training } \\
\text { for staff and users. }\end{array}$ \\
\hline
\end{tabular}


Lasserre (2012) reported that the health science librarian's expert search is important and essential as it supports evidence based training and clinical error prevention related to basic functions performed by clients. As an expert searcher CMLs perform his or her role well, using his or her skills and up to date knowledge in an ethically resource efficient manner, providing healthcare professionals and the community, as well as patients and their families.

\section{As a Communicator}

Cheek (2010) explained, CMLs can support the information needs of patients, their families, and the general public by not only locating but also delivering a range of information services in a user friendly manner. Librarians also help with a variety of other science related tasks, such as grant writing and data processing, academic correspondence, and translational research or the implementation of new technologies (Cooper \& Crum, 2013; Li et al., 2013; Sullo \& Gomes, 2016). CMLs perform the role of an expert communicator by understanding and transferring relevant information of patient to medical officers. It can perform the communicators' role by explaining psychological and social issues such as patient's fears, information on patient's disease, patient's feelings and emotions on impact of the disease, socio economic condition and family history to the physician (Aldrich \& Schulte, 2014; Polger, 2010; Sathe et al., 2007).

\section{As a Collaborator}

Though librarians have always been engaged in this role, its importance in collaboration started growing when more librarians were called to work on research teams and systematic review groups (Cruse \& 
Protzko, 2014; Murphy \& Boden, 2015). Continuing cooperation requires relationships based on trust, respect and partnership between different individuals. It entails exchanging information, experiences, and responsibilities, as well as a willingness to learn from one another. This requires understanding the role of others, making changes towards common goals and for management. The need to maintain collaborative activities that go beyond clinical care, such as administration, education, and counseling, is broadly relevant to the profession. Study and systematic analysis librarians also assist local personnel and doctors with advanced study and programs as liaisons to research teams, going beyond the position of an expert searcher (Dudden \& Protzko, 2011; Dilhani et al., 2020). In terms of their technical missions and trained skill sets in the management and dissemination of health information expertise, health sciences librarians and health informaticians have a "symbiotic" partnership (Aken, 2010). One of the new roles that health library librarians often address in the health information library literature is to integrate evidence based clinical information with physicians and patients into Electronic Medical Records (EMRs) (Albert, 2007; Avallone, 2014; Brandes et al., 2013; Ma et al., 2018).

\section{As a Patient Advocate}

According to the literature, CMLs provide patient advocacy through outreach and promotion, which requires a thorough understanding of the socio political and cultural climates outside of their institutions. Librarians in similar roles, according to Mayo and Pestonjee (2004), contributed to outreach projects for Spanish speaking communities as well as providing easier access to grey literature. In addition, librarians at the University of Texas hospital system have 
developed free or low cost informational materials for a "multicultural, predominantly low literacy patient population"; these English Spanish materials are available in both English and Spanish. When delivering care to the community, CMLs may work closely with medical practitioners and other health workers to reduce patient uncertainty about questions. Public librarians, according to Smith et al. (2014), will help the public by disseminating basic medical health related information and directing users to reliable, up to date information. Further, Schneider (2005) explained that CMLs are needed to assist families, patients, and the general public in locating trust worthy health records so that they can address problems with medical practitioners or seek care. In this type of role, Health Information Professionals (HIPs) often contribute to the development of collection in order to provide the best available health information services for each person, as well as act as expert searchers (Dudden \& Protzko, 2011; Greyson, 2011). Researchers addressing the increasing need for culturally competent HIP librarianship recently discussed about the growing need for health information materials and programs to serve LGBTQ (Lesbian, Gay, Bisexual, Transgender, Queer) patrons or patients and about their specific information needs, necessitating HIPs to cultivate and practice cultural competency in these populations (Hawkins et al., 2017; Mi \& Zhang, 2017; Morris \& Hawkins, 2016; Sullo \& Gomes, 2016).

\section{As a Content Manager for Scholarly Communication}

Despite the lack of literature on the topic, in general, many CMLs are urged for scholarly communication while performing their duties. Mears \& Bandy (2017) study revealed that with the growing number of web based library resources available for research and publishing, 
librarians could manage and promote those digital collections with a complex set of skills that encompass organization and presentation of online information. Schneider (2005) explained that CMLs provided technical support serving as website administrators, monitoring discussions, and even participating when appropriate. Via Scholarly correspondence and advanced web based information services, CMLs often empowers users to identify, objectively analyze, and use updated evidence based tools effectively and efficiently for optimum user access. A study of Harris et al. (2013) revealed that librarians are valuable partners in the field of scholarly communication and research because they have long been leaders of innovation related to the organization and distribution of knowledge: research starts at the library, and the result of research also ends up there. Accordingly with the advancement of Information Science and Data Technology, CMLs needs to develop and manage the corporate databases of healthcare organizations. Working as a data manager often requires knowledge of how to effectively identify, share, manage and protect large amounts of information, as well as intellectual property, copyright and licenses.

\section{As a Teacher}

While librarians have been referred to as teachers for many years, their pedagogical responsibilities have changed significantly. HIPs are expected to be able to present and sustain user interaction in active online and in person environments as online curricula and satellite medical education services increase in popularity (King et al., 2014). Accordingly, CMLs teach doctors, medical students and other affiliated healthcare professionals how to use medical software programmes, online databases, online resources; how to effectively use search engines for 
evidence based medicine and how to search the Internet for up to date, and other medical health related information and services. In this regard, instruction has shifted them from being a gate keeper of knowledge to being a teacher of self sufficiency. Librarians use a number of pedagogical approaches to provide evidence based practice guidance, and further study is required to decide which methods are the most successful (Alcock, 2017). Librarians have been referred to as mentors and teachers for many years, and today their educational role has evolved considerably. Accordingly, many scholarly commentators are of the opinion that the role of the CMLs are out of the library and more immersed in the user's world /profession.

Based on the literature, five main areas were identified as barriers for CMLs as shown in Table 2: educational, executive, organizational and management, cultural, technological and research.

\section{Discussion}

The literature review of the study itemizing the CMLs role provides research based evidence for developing or implementing new courses for degree programmes and students' pathways in Health Science Librarianship. Although the list of roles identified in this study is not exhaustive, it provides an informative overview, guidance and, detailed and comprehensive contexts that can inform the current and future curriculum development authorities of the issues in Health Science Librarianship. Mapping the identified roles (Figure 1) for LIS courses conducted in the Sri Lankan context shows the multiple skills, which should be developed by the CMLs. Figure 2 shows that CMLs is not always an isolated person but an important figure and that the link between CMLs and his services and the clinical team seems to work well. 


\section{Table 2}

Barriers for CMLs Based on the Reviewed Literature

\begin{tabular}{cc}
\hline No. Barriers/challenges for & Examples \\
CMLs involvement & \\
\hline
\end{tabular}

01. Educational

Low quality of current educational courses (Shokraneh, 2015; Sullo \& Gomes, 2016; Swanberg et al., 2016; Dilhani \& Ranasinghe, 2018)

Lack of proper and sustainable workshops and training programs (Swanberg et al., 2016)

Failure to identify the urgent need for a series of degree courses and professional programs on CML (Ma et al., 2018)

Lack of focus on EBM education (Blake \& Ballance, 2013)

Less proficiency in librarians and specialists (Sullo \& Gomes, 2016)

Familiarity with the clinical environment of librarians (Cruse \& Protzko, 2014)

Lack of medical terminology awareness (Morris et al., 2016; Murphy \& Boden,

2015; Perrier et al., 2014)

02. Cultural Personal Librarians have low self esteem (Murphy \& Boden, 2015)

Negative attitude of medical staff towards hospital librarians (Reid, 2011; Morris et al., 2016; Murphy \& Boden, 2015; Perrier et al., 2014)

Negative attitude of hospital management towards clinical librarians (Beschnett \& Bulger, 2013; Butson \& Pauly, 2013; Cooper \& Crum, 2013)

Lack of Physicians' knowledge about the clinical library services (Beschnett \& 


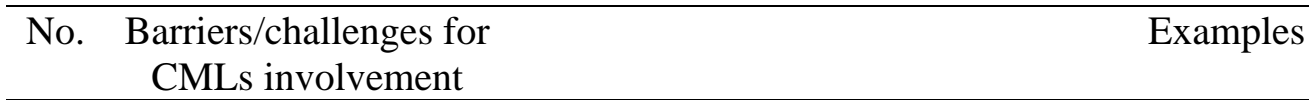

Bulger, 2013; Butson \& Pauly, 2013; Cooper \& Crum, 2013)

Group Lack of recognition for clinical library leadership among hospital management (Blake \& Ballance, 2013)

Lack of recognition of clinical library services among clinical groups (Cruse \& Protzko, 2014)

Poor interpersonal relationships (between clinical librarians and medical teams)

(Murphy \& Boden, 2015)

03. Executive organizational and management

04 Technological
Clinical librarians are underemployed in hospitals due to a lack of institutional roles (Beschnett \& Bulger, 2013; Butson \& Pauly, 2013; Cooper \& Crum, 2013)

Inadequate direction and management authority (Phillips \& Bonsteel, 2010; Aldrich \& Schulte, 2014; Bayrer et al., 2014; McDonald et al., 2014; Perrier et al., 2014)

Financial and budget issues (Aldrich \& Schulte, 2014; Bayrer et al., 2014; McDonald et al., 2014; Perrier et al., 2014)

Lack of sustainability and success of clinical library programs (Aldrich \& Schulte, 2014; Bayrer et al., 2014; MacDonald et al., 2014; Perrier et al., 2014)

Scarcity of computer hardware and software (Aldrich \& Schulte, 2014; Bayrer et al., 2014; McDonald et al., 2014; Perrier et al., 2014)

The dearth of evidence-based databasesand access to evidence-based databases (MLA, 2005; Beschnett \& Bulger, 2013; Butson \& Pauly, 2013; Cooper \& Crum, 2013; Cruse \& Protzko, 2014; Aldrich \& Schulte, 2014; Bayrer et al., 


\begin{tabular}{ccc}
\hline No. & $\begin{array}{c}\text { Barriers/challenges for } \\
\text { CMLs involvement }\end{array}$ & Examples \\
\hline
\end{tabular}

2014; McDonald et al., 2014; Perrier et al., 2014; Murphy \& Boden, 2015; Dilhani et al., 2020; Bass et al., 2020; Hackstadt, 2020; Hinrichs et al., 2020; McLaughlin, 2020; Tahmasebi et al., 2020)

Slow Internet connectivity (MLA, 2005; Beschnett \& Bulger, 2013; Butson \& Pauly, 2013; Cooper \& Crum, 2013; Cruse \& Protzko, 2014; Aldrich \& Schulte, 2014; Bayrer et al., 2014; McDonald et al., 2014; Perrier et al., 2014; Murphy \& Boden, 2015; Dilhani et al., 2020; Bass et al., 2020; Hackstadt, 2020; Hinrichs et al., 2020; McLaughlin, 2020; Tahmasebi et al., 2020)

05. Research

There are only a few studies on this topic (lack of identified issues and requirements, limited proposed solutions, and lack of evaluation methods for clinical library services). (MLA, 2005; Beschnett \& Bulger, 2013; Butson \& Pauly, 2013; Cooper \& Crum, 2013; Cruse \& Protzko, 2014; Aldrich \& Schulte, 2014; Bayrer et al., 2014; McDonald et al., 2014; Perrier et al., 2014; King \& Lapidus, 2015; Murphy \& Boden, 2015; Mohaghegh et al., 2019; Dilhani et al., 2020; Bass et al., 2020; Hackstadt, 2020; Hinrichs et al., 2020; McLaughlin, 2020; Tahmasebi et al., 2020) 
By highlighting the need for CMLs role in the country, Hashemianet et al. (2018) have pointed out that there are a number of difficulties and issues with implementing clinical librarianship programs, many of which could jeopardize the clinical librarianship's efforts and long term viability in Iran. According to Table 2, there are various difficulties and problems in letting CML into practice. More national and international research is needed to identify all of the professional, executive, cultural, and research obstacles and challenges for CML, as well as to propose appropriate solutions.

The present study provides the terminology used to explain the roles of CMLs in addition to terms: hospital librarian, healthcare librarian, and the information provider. When disasters merged with infectious diseases, non communicable diseases, disasters made by human and natural causes, CMLs have offered their service to clinical teams and the community. Based on the literature, it was found that CMLs seem to have impacted hospital settings through growing importance of consumer health literacy and of upgrading latest medical knowledge to medical teams.

The findings of this study provide an overview of the scenario regarding the Health Science Librarianship and the role of the CML in settings from elsewhere in the world. Though similar evidence related to the Sri Lankan context is not yet been published or not to be found, one cannot argue that it is not relevant to the local setting or such a need has not arisen yet. Instead, it is important to realize that the same issues/ situations/scenarios are in existence in our society, though the importance of the HIPs is not yet recognized in Sri Lanka. However, Medical Librarians' interactions with medical faculties, clinical staff, and hospital 
staff are not new, and they have been working together in certain missions. They are seen increasingly integrated with various types of activities in the health sector through various channels such as curricula in medical faculties, activities, and training programs of the Ministry of Health.

\section{Figure 2}

Framework for CML Role in Medical and Health-Related Team Developed by the Findings from the Literature

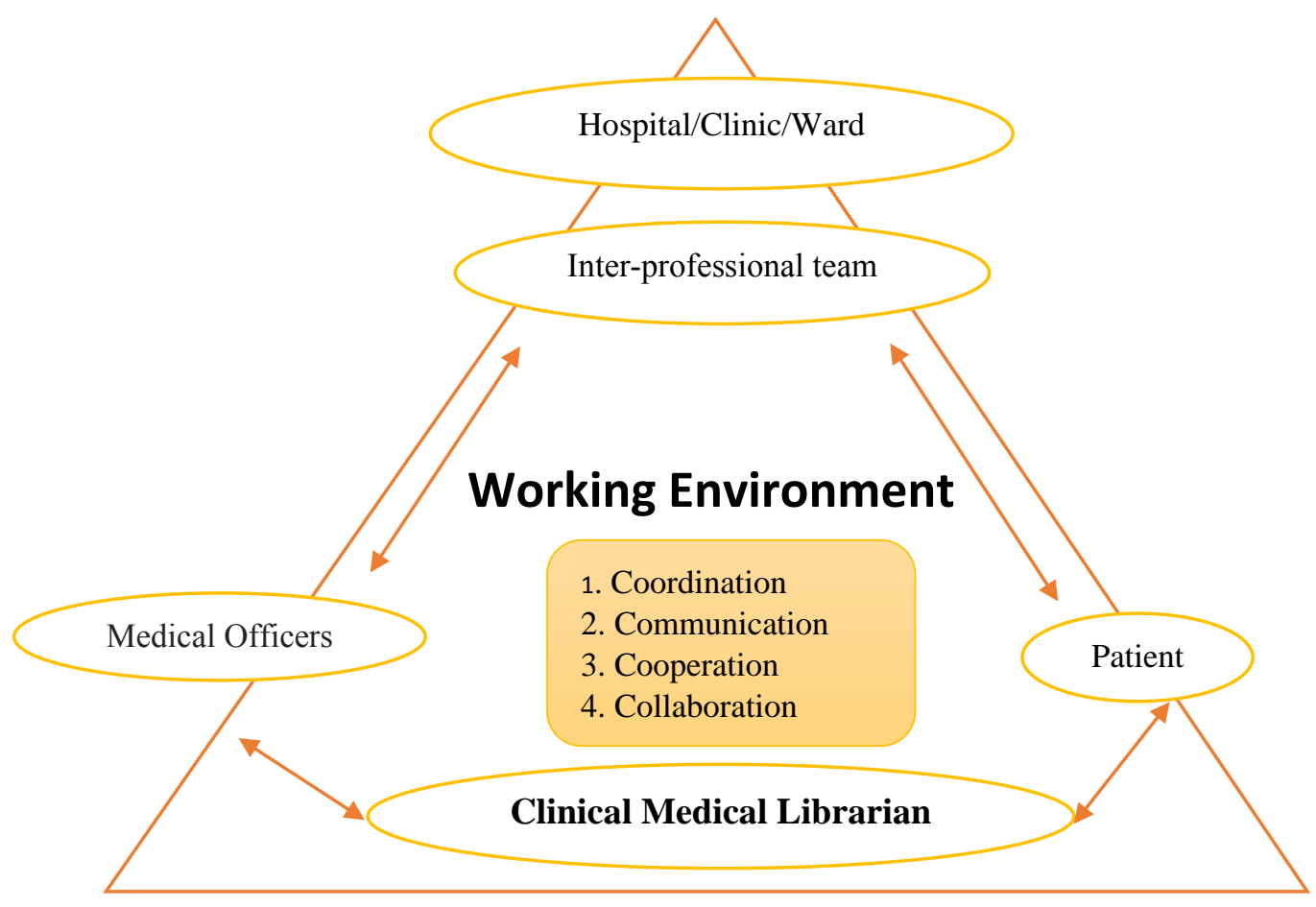

Note. Compiled by the researcher based on the literature

Specially in an Information era like today, research, evidence, and information are considered much important than before, and the emerging technologies have enabled all the processes of information 
dissemination. This has led policy makers to opt for many reliable approaches such as Evidence Based Practice (EBP) and EBM. Importantly, in healthcare service delivery, now it is the EBM gaining popularity in the practice of Medical Professionals where evidence is integrated with clinical practice. In this context, health/medical information professionals are much recognized. The approach of EBM is now believed to gain increased attention of the medical professionals in Sri Lanka. Therefore, CMLs and HIPs will have to play a significant role which was identified in this study. They should be provided with the training sessions to acquire the knowledge, skills, and expertise required to become competent information science professionals for the service.

\section{Conclusion and Recommendations}

\section{Conclusion}

The current study aimed to introduce the concept of the role of CMLs into the Sri Lankan context. While going through the literature, this study suggested that the CML's role is an essential part for the medical community. Therefore, the activities performed by CMLs are considered to be important and essential today. Besides, patients and their families also seek enormous medical information to clarify certain issues in the hospital setting where they need to have access to a CMLs. Table 1 illustrates required skills, abilities needed and specific duties for CMLs. Based on reviewed literature, it could identify roles of CMLs which have to be mapped into the emerging needs and future trends of the Sri Lankan context. Based on above mentioned skills, abilities and roles and duties, it could be recommended the importance of inclusion of the role of CMLs in the LIS programmes in Sri Lanka. 
This study reveals that producing CMLs with the necessary skills, knowledge, and qualifications is important. Hence a syllabus covering the role of CML is recommended to be incorporated into the existing LIS curriculum in Sri Lanka.

\section{Recommendations}

The overall objective in librarianship, to make information available at the point of need, has been strengthened by the philosophy of the programmes of CML. Therefore, it is essential to develop the required competencies via LIS educational programmes, which, in turn, require a proper syllabus to cater for CMLs. Accordingly, the present study suggests that the LIS educators in Sri Lanka have to pay attention to include the role of CMLs in the LIS curriculum. Further, more studies examining the findings of national and international are needed to identify all the opportunities and challenges to carry out a need analysis of the importance of CML's role in the LIS curriculum development and suggest appropriate solutions.

\section{Further Research}

Several research issues will need further investigation in the future, according to the findings:

1. Clinical librarianship is purely a profession, and what are the professional skills of a Clinical Librarian?

2. What are the research are as that should be explored on CMLs, and what are the most appropriate guidelines for future studies?

3. What is the professional identity of clinical librarians? Is CMLs a socially acceptable position? 
4. Is the current curriculum of health librarianship sufficient to produce appropriate clinical librarians? Or do you need special training in this regard?

5. If special training is required, does it need to be part of a university degree? Or should it be a short term or modular programme?

\section{Acknowledgements}

I would like to convey my sincere gratitude to Mrs. Sriyani Perera, Former Senior Assistant Librarian, Faculty of Medicine, University of Peradeniya, Sri Lanka for her encouragement and guidance in academic writing and achieving proficiency. 


\section{References}

Aken, S. N. (2010). Health informatics for Medical Librarians. Journal of the Medical Library Association, 98(2), 184-186. https://doi.org/ 10.3163/1536-5050.98.2.016

Albert, K. M. (2007). Integrating knowledge based resources into the electronic health record: history, current status, and role of librarians. Med Ref Serv Q, 26(3), 1-19.

Alcock, L. J. (2017). Low level evidence suggests that librarian led instruction in evidence based practice is effective regardless of instructional model. Evidence Based Library and Information Practice, 12(2), 163-165. https://doi.org/10.18438/B8XH3F

Aldrich, A. M., \& Schulte, S. J. (2014). Establishing a new clinical informationist role in an academic health sciences center. Medical Reference Services Quarterly, 33(2), 136-146. https://doi.org/ 10.1080/02763869.2014.897511

Avallone, C. (2014). Integrating information resources and services into the electronic health record (EHR). Journal of Medical Library Association, 102(4), 235. doi: http://dx.doi.org/10.3163/15365050.102 .4 .003

Bass, M. B., Allen, T. S., Vanderpool, A., \& Capdarest-Arest, N. (2020). Extending medical librarians' competencies to enhance collection organisation. Health Information \& Libraries Journal, 37(1), 70-77. https://doi.org/https://doi.org/10.1111/hir.12280

Bayrer, R., Beattie, S., Lucas, E., Melberg, D., \& Melton, E. (2014). What have we done for you lately? Measuring hospital libraries' contribution to care quality. Journal of Hospital Librarianship, 14(3), 243-249. https://doi.org/10.1080/15323269.2014.888514 
Beschnett, A., \& Bulger, J. (2013). Patient education and the hospital library: Opportunities for involvement. Journal of Hospital Librarianship, 13(1), 42-46. https://doi.org/10.1080/ 15323269.2013.743350

Blake, L., \& Ballance, D. (2013). Teaching evidence based practice in the hospital and the library: Two different groups, one course. Medical Reference Services Quarterly, 32(1), 100-110. https://doi.org/10.1080/02763869.2013.749143

Blake, L, Mears, K, Davies, Balance, D., Shipman, P., Connolly-Brown M, \& Gaines, J. K. (2014). Adapting an embedded model of librarianship, college by college. Medical Reference Services Quarterly, 33(3), 264-277.

Brady, K., \& Kraft, M. (2012). Embedded \& clinical librarianship: Administrative support for vital new roles. Journal of Library Administration, 52(8), 716-730. https://doi.org/ 10.1080/01930826.2012.748403

Brandes, S., Wells, K., \& Bandy, M. (2013). Invite yourself to the table: librarian contributions to the electronic medical record. Medical Reference Services Quarterly, 32(3), 358-364. https://doi.org/ $10.1080 / 02763869.2013 .807087$

Butson, L. C., \& Pauly, R. R. (2013). A librarian's role in enhancing patients' knowledge and self advocacy. Journal of Hospital Librarianship, 13(4), 362-372. https://doi.org/10.1080/ 15323269.2013.834194

Cheek, F. (2010). Research support in an academic medical center. Medical Reference Service Quarterly, Jan;29(1), 37-46. http://dx.doi.org/ $10.1080 / 02763860903485068$. 
Cooper, I. D., \& Crum, J. A. (2013). New activities and changing roles of health sciences librarians: a systematic review, 1990-2012. Journal of the Medical Library Association: JMLA, 101(4), 268-277. https://doi.org/10.3163/1536-5050.101.4.008

Cruse, P., \& Protzko, S. (2014). Librarian contributions to clinical practice guidelines. Medical Reference Service Quarterly, Jul;33(3), 327-34.

Dennett, L., Chatterley, T., Greyson, D., \& Surette, S. (2013). Research Embedded Health Librarianship: The Canadian Landscape. Journal of the Canadian Health Libraries Association, 34, 61-68. https://doi.org/10.5596/c13-024

Detlefsen, E. G. (2012). Teaching about teaching and instruction on instruction: A challenge for health sciences library education. Journal of the Medical Library Association, 100(4), 244-250. https://doi.org/10.3163/1536-5050.100.4.005

Dilhani, M. P. P., \& Ranasinghe, S. (2018). A study to examine the level of usage and awareness of national library of medicine classification (NLMC) system in health/medical libraries in Sri Lanka and factors associated in adopting it. Journal of the University Librarians Association of Sri Lanka, 21(1), 53. https://doi.org /10.4038/jula.v21i1.7911

Dilhani, M. P. P., Senevirathne, W., \& Abeysena, C. (2020). Accessibility of medical information by medical officers attached to divisional hospitals in rural Sri Lanka. Journal of the University Librarians Association of Sri Lanka, 23(1), https://doi.org/10.4038/j ula.v23i1.7963

Dudden, R. F., \& Protzko, S. L. (2011). The systematic review team: Contributions of the health sciences librarian. Medical Reference 
Services Quarterly, 30(3), 301-315. https://doi.org/10.1080/ 02763869.2011.590425

Egeland, M. (2015). Hospital librarians: From consumer health to patient education and beyond. Journal of Hospital Librarianship, 15(1), 65-76. https://doi.org/10.1080/15323269.2015.982944

Greyson, D. (2011). Open access and health librarians in 2011. Journal of the Canadian Health Libraries Association, 32, 45-49. https://doi.org/10.5596/c11-021

Greyson, D., Surette, S., Dennett, L., \& Chatterley, T. (2013). "You're just one of the group when you're embedded": Report from a mixedmethod investigation of the research embedded health librarian experience. Journal of the Medical Library Association, 101(4), 287-297. https://doi.org/10.3163/1536-5050.101.4.010

Hackstadt, A. (2020). Leadership, development, and expertise: A qualitative content analysis of scholarly communication librarian position announcements. Journal of Librarianship and Scholarly Communication, 8(1). https://doi.org/10.7710/2162-3309.2376

Hageman, J. R. (2019). Medical librarians can help providers improve clinical decision-making and education. Pediatric Annals, 48(2), e49-e50. https://doi.org/10.3928/19382359-20190116-01

Harris, R., Mayo, A., Prince, J. D., \& Tooey, M. J. (2013). Creating shared campus experiences: the library as culture club. Journal of the Medical Library Association: JMLA, 101(4), 254-256. https://doi.org/10.3163/1536-5050.101.4.005

Hashemian, M ., Zare-Farashbandi, F., Rahimi, A., Adibi, P., \& Yamani, N. (2018). Clinical Librarianship Challenges in Iran. Journal of the European Association for Helath and Libraries, 14(2), 23-26. 
Hawkins, B. W., Morris, M., Nguyen, T., Siegel, J., \& Vardell, E. (2017). Advancing the conversation: next steps for lesbian, gay, bisexual, trans, and queer (LGBTQ) health sciences librarianship. Journal of the Medical Library Association: JMLA, 105(4), 316-327. https://doi.org/10.5195/jmla.2017.206

Hinrichs, R. J., Bakker, C. J., Brigham, T. J., Ginier, E. C., Stevens, G. A., \& Alpi, K. M. (2020). Exploring interprofessional collaboration and attitudes of health sciences librarians. Journal of the Medical Library Association: JMLA, 108(3), 440-451. https://doi.org/ 10.5195/jmla.2020.804

Joshi, M., Ali A. M., Ullah, M., \& Kuruppu, C. (2014). International trends in health science librarianship part 12: South Asia (India, Pakistan and Sri Lanka). Health Information and Libraries Journal, 31(4), 318-324. https://doi.org/10.1111/hir.12085

King, S. B., \& Lapidus, M. (2015). Metropolis revisited: the evolving role of librarians in informatics education for the health professions. Journal of the Medical Library Association: JMLA, 103(1), 14-18. https://doi.org/10.3163/1536-5050.103.1.003

King, S., Murray, H., \& MacDonald, K. (2014). Evolving a collaborative matrix for teaching informatics online to health sciences students at the Massachusetts College of Pharmacy and Health Sciences. Journal of the Canadian Health Libraries Association / Journal de l'Association Des Bibliothèques de La Santé Du Canada, 31(3), 109-114. https://doi.org/10.5596/c10-029

Lappa, E. (2004). Clinical Librarianship (CL): A Historical perspective. Electronic Journal of Academic and Special Librarianship, 5(2-3).

Lasserre, K. (2012). Expert searching in health librarianship: A literature 
review to identify international issues and Australian concerns. Health Information and Libraries Journal, 29(1), 3-15. https://doi.org/10.1111/j.1471-1842.2011.00974.x

Li, M., Chen, Y. B., \& Clintworth, W. A. (2013). Expanding roles in a library-based bioinformatics service program: a case study. Journal of the Medical Library Association: JMLA, 101(4), 303-309. https://doi.org/10.3163/1536-5050.101.4.012

McDonald, K. A., Hrynchak, P. K., \& Spafford, M. M. (2014). Evidence based practice instruction by faculty members and librarians in North American optometry and ophthalmology programs. Journal of the Medical Library Association: JMLA, 102(3), 210-215. https://doi.org/10.3163/1536-5050.102.3.013

Ma, J., Stahl, L., \& Knotts, E. (2018). Emerging roles of health information professionals for library and information science curriculum development: A scoping review. Journal of the Medical Library Association, 106(4), 432-444. https://doi.org/10.5195/jmla.2018.354

Mayo, H. G., \& Pestonjee, S. F. (2004). Creating understandable health information Helen G. Mayo. Journal of Hospital Librarianship, 4(4), 113-118. https://doi.org/10.1300/J186v04n04_10

McLaughlin, L. K. (2020). Hospital librarians: Partners in changing times. Journal of Hospital Librarianship, 20(4), 361-367. https://doi.org/ 10.1080/15323269.2020.1819759

Mears, K., \& Bandy, S. L. (2017). Investigating the need for scholarly communications positions in Association of Academic Health Sciences Libraries member institutions. Journal of the Medical Library Association, 105(2), 145-149. https://doi.org/10.5195/ jmla.2017.208 
Medical Library Association. (2005). Role of expert searching in health sciences libraries. Journal of the Medical Library Association: JMLA, 93(1), 42-44. https://pubmed.ncbi.nlm.nih.gov/15685273

Medical Library Association. (2017). MLA competencies for lifelong learning and professional success. https://www.mlanet.org/ page/competencies

Mi, M., \& Zhang, Y. (2017). Culturally competent library services and related factors among health sciences librarians: an exploratory study. Journal of the Medical Library Association: JMLA, 105(2), 132-138. https://doi.org/10.5195/jmla.2017.203

Mohaghegh, N., Dehnad, A., Zarghani, M., Abdekhoda, M., \& Mohamadzadeh, S. (2019). Clinical residents' perception of clinical librarian services in Iranian teaching hospitals. Libres, 29(1), 37-50.

Morris, M., Boruff, J. T., \& Gore, G. C. (2016). Scoping reviews: establishing the role of the librarian. Journal of the Medical Library Association : JMLA, 104(4), 346-354. https://doi.org/10.3163/15365050.104 .4 .020

Morris, M., \& Hawkins, B. (2016). Towards a new specialization in health librarianship: LGBTQ health. Journal of the Canadian Health Libraries Association / Journal de l'Association Des Bibliothèques de La Santé Du Canada, 37(1), 20-23. https://doi.org/10.5596/c16007

Murphy, S. A., \& Boden, C. (2015). Benchmarking participation of Canadian university health sciences librarians in systematic reviews. Journal of the Medical Library Association: JMLA, 103(2), 73-78. https://doi.org/10.3163/1536-5050.103.2.003

Perrier, L., Farrell, A., Ayala, A. P., Lightfoot, D., Kenny, T., Aaronson, E., 
Allee, N., Brigham, T., Connor, E., Constantinescu, T., Muellenbach, J., Epstein, H. A. B., \& Weiss, A. (2014). Effects of librarian provided services in healthcare settings: A systematic review. Journal of the American Medical Informatics Association : JAMIA, 21(6), 1118-1124. https://doi.org/10.1136/amiajnl-2014002825

Phillips, R. M. \& Bonsteel, S. H. (2010). The faculty and information specialist partnership: stimulating student interest and experiential learning. Nurse Educator, 35(3), 136-138. https://doi.org/10.1097/ NNE.0b013e3181d95090

Polger, M. A. (2010). The Informationist: Ten years later. Journal of Hospital Librarianship, 10(4), 363-379. https://doi.org/10.1080/ 15323269.2010.514556

Reid, M. A. (2011). Evaluating the impact of Clinical Management Librarian service in a UK teaching hospital. $7^{\text {th }}$ Shangai International Library Forum. https://doi.org/10.13140/ 2.1.3163.9681

Sathe, N. A., Jerome, R., \& Giuse, N. B. (2007). Librarian perceived barriers to the implementation of the informationist/information specialist in context role. Journal of the Medical Library Association: JMLA, 95(3), 270-274. https://doi.org/10.3163/15365050.95.3.270

Schneider J. (2005). Information therapy and librarians: Quality prescriptions for health. Journal of Hospitel Librarianship, 5(4), 7380.

Shokraneh, F. (2015). Clinical librarianship in Iran. Academic Medical Librarians and Libraries: Roles of Medical Librarians in Clinical 
Decision Making, 14(c), 23-26.

Smith, C. A., Hundal, S., \& Keselman, A. (2014). Knowledge gaps among public librarians seeking vaccination information: A qualitative study. Journal of Consumer Health on the Internet, 18(1), 44-46. https://doi.org/10.1080/15398285.2014.869168

Sullo, E., \& Gomes, A. W. (2016). A profession without limits: The changing role of reference librarians. Medical Reference Services Quarterly, 35(2), 145-157. https://doi.org/10.1080/ 02763869.2016.1152141

Swanberg, S. M., Dennison, C. C., Farrell, A., Machel, V., Marton, C., O’Brien, K. K., Pannabecker, V., Thuna, M., \& Holyoke, A. N. (2016). Instructional methods used by health sciences librarians to teach evidence based practice (EBP): A systematic review. Journal of the Medical Library Association: JMLA, 104(3), 197-208. https://doi.org/10.3163/1536-5050.104.3.004

Tahmasebi, M., Adibi, P., Zare-Farashbandi, F., Papi, A., \& Rahimi, A. (2020). The educational role of clinical informationist on improving clinical education among medical students: Based on Kirkpatrick model. Journal of Education and Health Promotion, 9. https://doi.org/10.4103/jehp.jehp_439_19

Tan, M. C., \& Maggio, L. A. (2013). Expert searcher, teacher, content manager, and patient advocate: an exploratory study of clinical librarian roles. Journal of the Medical Library Association: JMLA, 101(1), 63-72. https://doi.org/10.3163/1536-5050.101.1.010

Wilson, V. (2008). Academic librarians have concerns about their role as teachers. Evidence Based Library and Information Practice, 3(3), 73-75. https://doi.org/10.18438/B82K6H 